\title{
Soil-Structure Interaction Effect on Fragility Curve of 3D Models of Concrete Moment-Resisting Buildings
}

\author{
Ali Anvarsamarin (D), ${ }^{1}$ Fayaz Rahimzadeh Rofooei $(\mathbb{D}),{ }^{2}$ and Masoud Nekooei ${ }^{1}$ \\ ${ }^{1}$ Department of Civil Engineering, Science and Research Branch, Islamic Azad University, Tehran, Iran \\ ${ }^{2}$ Civil Engineering Department, Sharif University of Technology, Tehran, Iran \\ Correspondence should be addressed to Fayaz Rahimzadeh Rofooei; rofooei@sharif.edu
}

Received 21 August 2017; Revised 23 January 2018; Accepted 27 February 2018; Published 19 April 2018

Academic Editor: Sara Muggiasca

Copyright (c) 2018 Ali Anvarsamarin et al. This is an open access article distributed under the Creative Commons Attribution License, which permits unrestricted use, distribution, and reproduction in any medium, provided the original work is properly cited.

\begin{abstract}
This paper presents the probabilistic generation of collapse fragility curves for evaluating the performance of 3D, reinforced concrete (RC) moment-resisting building models, considering soil-structure interaction (SSI) by concentration on seismic uncertainties. It considers collapse as the loss of lateral load-resisting capacity of the building structures due to severe ground shaking and consequent large interstory drifts intensified by $P-\Delta$ effects as well as the strength and stiffness deterioration of their lateral load carrying systems. The estimation of the collapse performance of structures requires the relation between the intensity measure (IM) and the probability of collapse that is determined using the generated collapse fragility curves. Considering a number of 6-, 12-, and 18-story, 3D, RC moment-resisting buildings, two scalar IMs are employed to estimate their collapse fragility curve. On the other hand, the effect of the site soil type on the collapse fragility curves was taken into account by considering the soil-structure interaction. According to the obtained results, adopting the average of spectral acceleration (Saavg) intensity measure is more efficient in capturing the effect of the inherent uncertainties of the strong ground motions on the structural response parameters. In addition, considering the SSI for soil type D with shear-wave velocity of $180 \mathrm{~m} / \mathrm{s}$ to $360 \mathrm{~m} / \mathrm{s}$ reduces the median of intensity measure $\left(\mathrm{IM}=\mathrm{Sa}\left(T_{1}\right)\right)$ of fragility curve in 6-, 12-, and 18-story buildings by $4.92 \%, 22.26 \%$, and $23.03 \%$, respectively.
\end{abstract}

\section{Introduction}

According to a conventional definition, the collapse of buildings during or within short time after earthquake excitation is due to the loss of their structural system integrity that in turn is caused by generation of large deformation or force demands in their primary structural components. The stochastic nature of the strong ground motions as well as the fact that no numerical approach can exactly model all the features of complex structural behavior makes the seismic collapse analysis of structures very difficult. Probabilistic techniques on the other hand have introduced the combination of variable possible sources in collapse assessment process as well as collapse potential of available buildings in the form of collapse probability [1-4]. The probabilistic estimation of maximum story drift demands by considering a 9-story, moment-resisting frame building subjected to severe ground motions was improved by Stoica et al. [5]. They concluded that the three-parameter log-normal distribution describes maximum story drifts at higher values of spectral acceleration more rationally; statistically adding values to replace truncated data points provides better fitness in maximum drift demand prediction when the structure is close to the onset of dynamic instability, and the least-squares fitting of the log-normal distribution yields parameters that provide an improved fit compared to that from maximum likelihood estimation and the method of moments. Current seismic design codes do not take into account duration effects and are mainly based on spectral acceleration. This fact is because of the lack of actual recorded for long duration ground motion and debates about whether artificial records can take place of recorded motions. In the last few years, many long duration ground motions have been recorded after events such as Tohoku. This led to few researches on the effect of considering ground motion duration on buildings damage and risk of collapse (e.g., [6]). 
In general, the probabilistic approaches for assessment of the buildings collapse potential use the very basic assumption that the effects originated from the uncertainties existing in the earthquake records' characteristics are independent of the uncertainties in the numerical modeling and prediction of seismic hazard level. A performance target in collapse level can be considered as a tolerable collapse probability in a given hazard level. Currently, collapse fragility curve is used as one of the most essential probabilistic approaches to assess a structure collapse measurement. A set of IDA analyses can play a vital role in determining estimation parameters and in turn determining collapse fragility curve. The seismic collapse safety of the older RC frames which was designed and constructed prior to the 1970s was used to study the effect of two structural parameters such as the transverse reinforcing ratio and the flexural strength ratio of the column to the beam. As a result of a study, it was found out that the two ratios that interacted with each other must be considered to appreciate the collapse risk of a building [7]. The experience of recent decade revealed that, in big, heavy, and rigid buildings founded on soft and stiff soils, SSI effects are of high importance in terms of the buildings stability. In buildings founded on soft and stiff soil, SSI increases the fundamental period of system and decreases the base shear force. This study uses 6- and 12-story $\mathrm{RC}$ buildings with intermediate moment frames system as well as an 18-story RC building with special moment frame system to evaluate SSI effects on the determination of the demand and capacity of collapse and finally to determine the structural fragility curves. Finally, by studying the dispersion of IDA curves and the extent of the results dependency on seismic records properties the appropriate IM will be selected among two mentioned scalar IMs. Soil-structure interaction (SSI) can alter the performance of structure totally including its dynamic characteristics, response maxima, and, more importantly, distribution of nonlinear response through structure where the accurate calculation of it is vital for the performance evaluation.

\section{Global Collapse}

The study of global collapse was triggered by considering $P$ $\Delta$ effects on seismic response. Although hysteresis models considered positive postyielding stiffness, the structure tangent stiffness became negative under large $P-\Delta$ effects which in turn lead to the systemic collapse. Structural performance assessment needs a numerical criterion. According to FEMA 2000, the IDA approach is proposed to estimate the structural capacity of the buildings. In addition, FEMA 2000 is classified as the point of occurrence of collapse based on the following conditions: numerical nonconvergence in structural analysis algorithm and the occurrence of a slope equal to $20 \%$ of the initial elastic slope in the IDA curve and exceedance of the maximum internal drift ratio above \%10. Jalayer and Cornell used IDA concept to estimate total dynamic instability capacity of a regular RC structure [8]. Robust fragility assessment for Cloud Analysis considering the global dynamic instability and IDA can also be found in provided detail by Jalayer et al. [9]. In addition, their research includes details about how a modified version of the Cloud Analysis can officially handle the existence of records that trigger collapse. Haselton and Dierlin evaluated the collapse risk of 30 4-story buildings with special moment frame designed in accordance with ASCE9-02. According to their results, likelihood of structural collapse for earthquakes with a return period of 2475 years ranges from $3 \%$ to $20 \%$ with a mean of $11 \%$. Their study revealed that the minimum essential base shear determined by ASCE7-02 is an important element guaranteeing almost a fixed collapse risk for buildings with different heights [10]. Haselton et al. studied the collapse capacity of 1- to 20-story buildings with special moment frames. Their study showed that, for a 2\%-in-50 years earthquake, the mean collapse probability in the studied buildings is about $11 \%$ [11]. Lignos et al. used the results of a collapse test conducted on a 4story steel moment frame on shaking table of E-Defence Laboratory and derived the essential parameters required for modeling the collapse reliability of buildings. According to their results, the difference in collapse capacity in regular plan buildings is not significant between 3D and 2D models [12]. Rajeev and Tesfamariam demonstrated fragility based seismic vulnerability of structures with consideration of soft story (SS) and quality of construction (CQ) on three-, five-, and nine-story RC frames designed prior to the 1970s. They developed probabilistic seismic demand model (PSDM) for those gravity load designed structures, using the nonlinear finite element analysis, considering the interactions between SS and CQ. Result of their study showed the sensitivity of the model parameter to the interaction of SS and CQ [13]. Palermo et al. evaluated the efficiency of current modeling techniques in predicting the collapse capacity of the studied structures. The results of numerical modeling were compared with real samples of L'Aquila earthquake in Italy. According to the study, modern techniques have better capability of predicting the collapse capacity of structures [14].

The median collapse intensity can be visualized through the concept of incremental dynamic analysis (IDA), in which individual ground motions are scaled to increasing intensities until the structure reaches a collapse point [15]. To consider the uncertainties of seismic intensity measure predictions, this method normalizes an earthquake record in a manner to cover a wide range of intensity measure. On the other hand, acceptable numbers of seismic records are required to take the uncertainties of the frequency content and spectral shape of earthquakes into account. The relationship between engineering demand parameter (EPD) registered in an IDA and one or more seismic intensity measures (IMs) which describe the normalized earthquake records applied to the structure is called IDA curve. Collapse assessment of structures based on IDA curves necessitates the selection of fit IM and a fit seismic demand (DM) used to construct these IDA curves as well as variability in the set of ground motions considered in the analysis [16]. Intensity measure should be selected in a manner to be connected to the main record using a scale factor. PGA, PGV, and elastic spectral acceleration in fundamental period of a structure for $5 \%$ of critical damping are the most conventional indices, which can be used as scalar or vector indices. The selection of an IM depends on the efficiency in terms of seismic intensity and on 


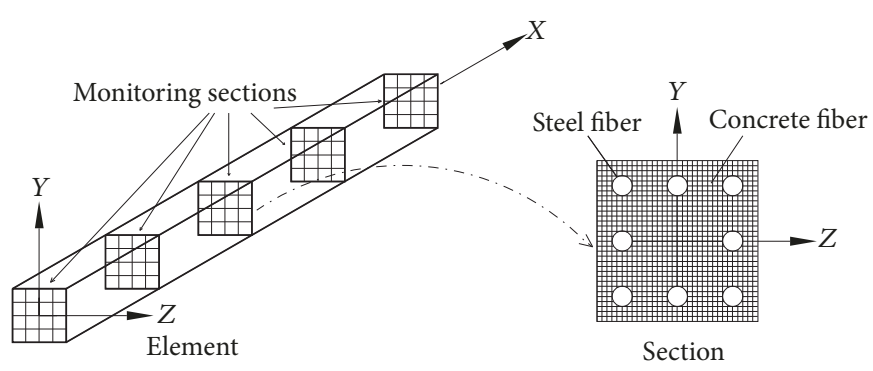

FIgURE 1: Modeling flexural members using fiber command.

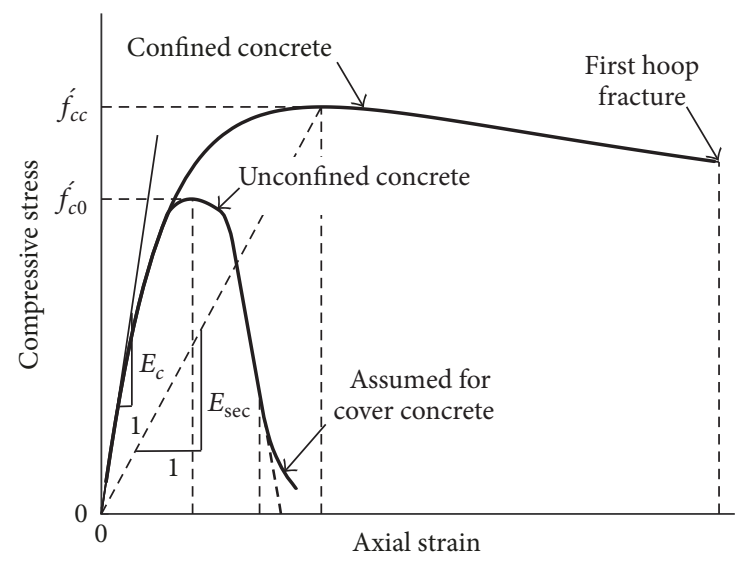

FIGURE 2: Determining the compressive strength of confined concrete in accordance with Mander model.

the sufficiency in terms of the number of earthquake records. Generally, if the selected IM can reduce the dispersion of IDA results, it will have a better efficiency. In addition, if the selected IM can reduce the dependency of demand and seismic capacity distributions on the record selection, it will provide a better sufficiency. Generally, the aim of this feature is to reduce the dependency of results on records specifications including magnitude and distance from fault. If there are no near field earthquake-caused directivity effects in seismic records, selecting $\mathrm{Sa}\left(T_{1}, 5 \%\right)$ for moderate height structures where the first mode is the governing mode will be sufficient for describing the primary specifications of ground motion in structural responses [17]. In this way, by estimating seismic demand and capacity, sufficient and appropriate data of structure response can be obtained using fewer records (ranging from 10 to 20 earthquake records) with no dependency of results on record intensity and fault distance. Spectral acceleration average (Saavg) was introduced as the geometric mean of the acceleration response spectra points of seismic record at $5 \%$ of damping $[18,19]$.

Eads et al. showed that Saavg is generally more efficient and more sufficient and provides more stable collapse risk estimates than $\mathrm{Sa}\left(T_{1}\right)$ after evaluating the efficiency and sufficiency of a similar IM for collapse prediction using nearly 700 moment-resisting frame and shear wall structures of various heights [20]. A recasting of conditional spectrum record selection which is based on Saavg over a period range as the conditioning IM was presented by Kohrangi et al. [21].
Two sets of ground motions consisting of ordinary and nearfault records were used for evaluating the IMs on 2D RC frame structures with fixed base and isolated at the base. The most suitable IMs for predicting the considered different demand parameters and types of structure were identified in terms of both efficiency and sufficiency [22]. Luco and Cornell introduced several new scalar IMs for performance assessment of three steel frames of moderate-to-long period subjected to the 31 near-source and/or 59 ordinary ground motions records. These IMs were compared by describing the "efficiency" and "sufficiency" of an IM that can be determined by nonlinear dynamic analysis of the building under the selected ground motion records, and linear regression analysis. One of the considered IMs has been found to be relatively efficient and sufficient for the near-source as well as the ordinary earthquake records [23].

By reviewing the dispersion of IDA curve and the dependency of results on seismic records properties, this study selects the best fit IM among $\operatorname{Saavg}\left(T_{i}, 5 \%\right)$ and $\mathrm{Sa}\left(T_{1}, 5 \%\right)$.

\section{Numerical Modeling}

The open system for earthquake engineering simulation (OpenSees) program [24] is used for numerical modeling and analysis of the considered structural models. The force based element (FBE) and displacement based element (DBE) are two techniques by OpenSees software for modeling the nonlinear behavior of different structural members. In this study, nonlinearBeamColumn command is adopted to model the structural members using the fiber section, which is based on the force formulation, and considers the spread of plasticity along the element [25]. This is the most economical and accurate approach to investigate the seismic behavior of RC structures. Figure 1 shows the unidirectional steel and concrete layers in flexural members [26, 27]. Accuracy of the solution in FBE can be improved by increasing either the number of integration points or the number of elements.

Concrete02 material commands are used for concrete modeling in OpenSees software. However, RC members have been generally confined using stirrups, which leads to the enhanced stress-strain constitutive behavior. Therefore, the cover and core concrete can be modeled as different materials, using the same material type, but different stress and strain characteristics and different material tags. The compressive strength and strain of core concrete are determined using Mander-Priestley model [28] (Figure 2) in order to promote 
modeling accuracy. The aforementioned model is used as a general model to take confinement effects into account in different columns. Lateral reinforcements have different types such as circular, spiral, and rectangular stirrup with or without tie. This project considered the structural members sections as rectangular sections with tie stirrup exposed to the unidirectional loads. This issue has been studied widely with regard to the stress-strain relationship of confined concrete using Mander's equation:

$$
\begin{aligned}
& f_{c}=\frac{\dot{f}_{c c} X r}{r-1+X^{2}}, \\
& X=\frac{\varepsilon_{c}}{\varepsilon_{c c}}, \varepsilon_{c c}=\left[R\left(\frac{f_{c c}}{f_{c 0}}-1\right)+1\right] \varepsilon_{c 0}, r=\frac{E_{c}}{E_{c}-E_{s e c}},
\end{aligned}
$$

where $X$ represents ratio of strain to strain at maximum stress, $f_{c c}$ represents the maximum stress of confined concrete, $r$ is the ratio of the primary module of elasticity to the difference of the primary and secondary modules of elasticity, and $R$ is an empirical parameter obtained from different tests. This model suggests $R=3$ and $R=6$ for high strength concrete and typical concrete, respectively. The following equation gives the maximum stress of confined concrete based on Mander relation:

$$
\begin{aligned}
\dot{f}_{c c} & =\dot{f}_{c o}\left(2.254 \sqrt{1+\frac{7.94 \dot{f}_{1}}{f_{c o}^{\prime}}}-\frac{2 \dot{f}_{1}}{\dot{f}_{c o}}-1.254\right), \\
\dot{f}_{1} & =\frac{1}{2} K_{e} \rho_{s} f_{y h}, \\
E_{s e c} & =\frac{\dot{f}_{c c}}{\varepsilon_{c c}}
\end{aligned}
$$

The effective confinement coefficient $K_{e}$ is a very important parameter. It shows the effectiveness of different lateral stirrups. Mander et al. introduced different relations for different lateral reinforcements, especially circular and spiral stirrups, in order to calculate $K_{e}$.

$$
K_{e}=\frac{1-k S / D^{\prime \prime}}{1-\rho_{c c}},
$$

where $\rho_{c c}$ represents the ratio of longitudinal reinforcement area to core concrete section area, $\rho_{s}$ is the ratio of lateral confining lateral reinforcements volume to the confined core concrete volume, $f_{y h}$ is the yielding stress of lateral reinforcements, and $k$ is 0.5 for spiral and 1.0 for stirrup reinforcement.

The stress-strain curves of confined core concrete in structural element sections were determined using KSU-RC program [29] and Mander relationship. Rayleigh damping is used in modeling of structures. It should be noted that, to avoid numerical instability or nonconvergence, Steel02 command is used for reinforcing bars modeling in OpenSees software. In Steel02 command, the strain-hardening ratio is considered to be equal to 0.01 .
3.1. Soil-Structure Model. One of the issues that can affect the seismic response of structures is soil-structure interaction (SSI), which has been investigated by many researches (e.g., [30-32]). Depending on the stiffness of the soil, the seismic performance and energy dissipation of structures can significantly be changed by considering the SSI effects. Khoshnoudian et al. showed that soil flexibility increases the dynamic instability of structural system and collapse strength reduction factor highly decreases by increasing nondimensional frequency [30]. Shakib and Homaei showed that SSI reduces the structural seismic capacities, ductile deformation, and life-safety confidence level [31]. In addition, they showed that SSI increases the drift demand. Behnamfar and Banizadeh showed that, with a flexible base, the location of maximum drift moves to the first story where the most severe vulnerability is observed [32]. They showed that SSI changes the pattern of distribution of vulnerability, especially for the beams of shear wall buildings, and increases the seismic vulnerability on soft soils.

Due to the importance of preventing the collapse of structures under severe ground motions and the considerable effects of SSI on the structural seismic response, the effects of SSI on seismic collapse capacity of RC moment-resisting buildings are investigated in the present study. The soilstructure model is then completed by attaching the soilfoundation element at the base of the superstructure. To define the coefficients of this element taking also into account soil nonlinearity, established parameters of the cone model are modified based on the equivalent linear approach. To model the soil effect under the structure, the cone model (monkey-tail model) was used with presented modifications. Figure 3 shows the schematic model intended for soilfoundation element based on cone model concept [33].

Table 1 presents the properties of the cones and discreteelement models representing a rigid rectangular foundation with area $A_{0}$ and area moment of inertia about the axis of rotation $I_{0}$ (for torsional rotation, $I_{0}$ is polar moment of inertia) on surface of homogeneous half-space. In this Table, $v$ is Poisson's ratio of the soil, $V s$ is the shear-wave velocity of the soil, $V p$ is the $P$-wave velocity of the soil, $\rho$ is density, and $G$ is the shear modulus of the soil. It should be noted that stiffness coefficients of foundation in Table 1 were calculated for rectangle shaped foundations $(L \times B, L>B)$.

To model substructure using the monkey-tail model, two nodes at the same location have been defined at base level. Using spring stiffness independent of frequency and taking a damping coefficient into account, the frequency dependence of the interaction is the easiest way to consider the effects of SSI. The nodes have been connected by multiple uniaxial material objects based on cone model. All degrees of freedom in first node and vertical degree of freedom in second node have been constrained. The springs and dampers have been connected from the first node to the second node using a zero-length element and the vertical degree of freedom was ignored. In addition, the masses of separated model have been applied to the second node. The soil Poisson's coefficient, soil damping ratio, and soil density, as the essential parameters for soil modeling, were considered to be $0.33,0.05$, and $2000 \mathrm{~kg} / \mathrm{m}^{3}$. 


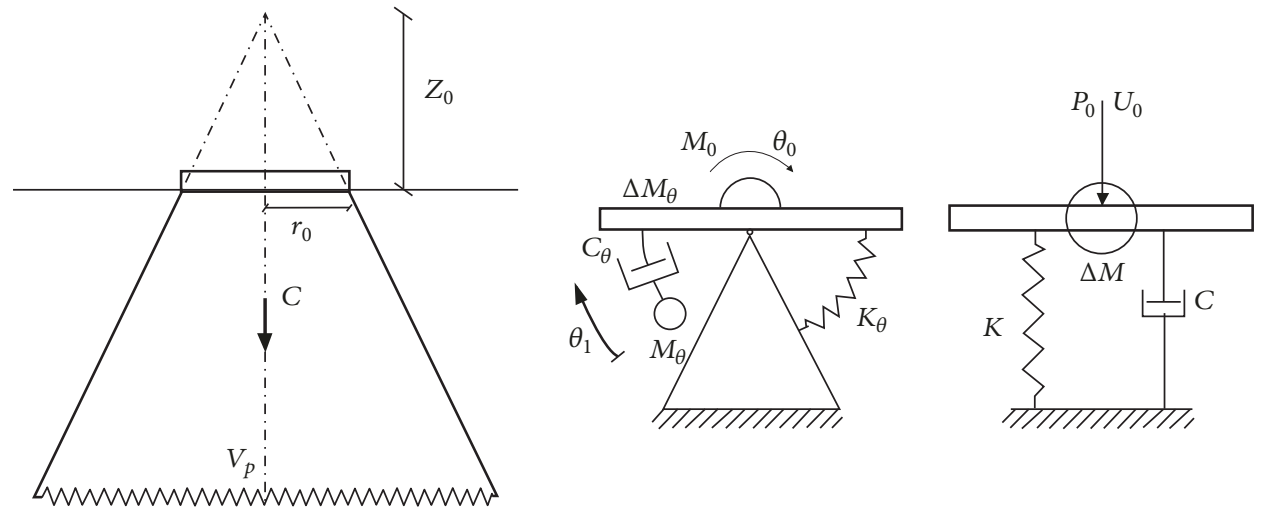

FIgURE 3: Cone model layout and equivalent lumped elements for soil replacement model.

TABLE 1: Con model of properties of the rectangular foundation on a homogeneous half-space [33].

\begin{tabular}{|c|c|c|c|}
\hline Motion & Horizontal & Rocking & Torsion \\
\hline Equivalent radius $\left(r_{0}\right)$ & $\sqrt{\frac{A_{0}}{\pi}} \quad \sqrt{\frac{A_{0}}{\pi}}$ & $\sqrt[4]{\frac{4 I_{0}}{\pi}}$ & $\sqrt[4]{\frac{2 I_{0}}{\pi}}$ \\
\hline Aspect ratio $z_{0} / r_{0}$ & $\frac{\pi}{8}(2-v) \quad \frac{\pi}{4}(1-v)\left(\frac{V}{V_{s}}\right)^{2}$ & $\frac{9 \pi}{32}(1-v)\left(\frac{V}{V_{s}}\right)^{2}$ & $\frac{9 \pi}{32}$ \\
\hline Poisson's ratio & All values $\quad v \leq \frac{1}{3} \quad \frac{1}{3}<v \leq \frac{1}{2}$ & $v \leq \frac{1}{3} \quad \frac{1}{3}<v \leq \frac{1}{2}$ & All values \\
\hline Wave velocity (V) & $V_{p} \quad 2 V_{s}$ & $2 V_{s}$ & $V_{s}$ \\
\hline Added mass & $0 \quad 0 \quad 2.4\left(v-\frac{1}{3}\right) \rho A_{0} r_{0}$ & $0 \quad 1.2\left(v-\frac{1}{3}\right) \rho A I_{0} r_{0}$ & 0 \\
\hline $\begin{array}{l}\text { Lumped-parameter } \\
\text { model }\end{array}$ & $\begin{array}{c}K_{x}=\frac{G B}{2-v}\left[3.4\left(\frac{L}{B}\right)^{0.65}+1.2\right] \\
K_{y}=\frac{G B}{2-v}\left[3.4\left(\frac{L}{B}\right)^{0.65}+0.4 \frac{L}{B}+0.8\right] \\
K_{z}=\frac{G B}{1-v}\left[1.55\left(\frac{L}{B}\right)^{0.75}+0.8\right] \\
C=\rho \cdot V \cdot A_{0} \\
C^{\prime}=\frac{2 \xi_{0}}{\omega_{0}} K, m^{\prime}=\frac{\xi_{0}}{\omega_{0}} C\end{array}$ & $\begin{array}{c}K_{x x}=\frac{G B^{3}}{1-v}\left[0.4\left(\frac{L}{B}\right)+0.1\right] \\
K_{y y}=\frac{G B^{3}}{1-v}\left[0.4\left(\frac{L}{B}\right)^{2.4}+0.034\right. \\
K_{z z}=G B^{3}\left[0.53\left(\frac{L}{B}\right)^{2.45}+0.51\right. \\
C_{\theta}=\rho \cdot V \cdot I_{0}, C_{\theta}^{\prime}=\frac{2 \xi_{0}}{\omega_{0}} K_{\theta} \\
M_{\theta}=\rho I_{0} z_{0}, m_{\theta}^{\prime}=\frac{\xi_{0}}{\omega_{0}} C_{\theta}\end{array}$ & \\
\hline
\end{tabular}

3.2. The Considered Structural Models. The selection of the building is based on the different period range which included mid-to-high-rise buildings on soil type D. Three 6-, $12-$, and 18-story, 3D reinforced concrete moment-resisting buildings with the fundamental periods of $0.86,1.38$, and 1.97 second were considered and designed according to the ACI 318-08 and ASCE 7-10 code requirements [34, 35]. These structural models are assumed to be of administrative buildings type with the same plan dimensions, located on soil type D according to the ASCE 7-10 code [35]. The structural system of the 6- and 12-story buildings is intermediate moment-resisting buildings, while the 18-story building is considered as special moment-resisting building. The specified compressive strength of concrete is $240 \mathrm{~kg} / \mathrm{cm}^{2}$ in the 6 and 12-story buildings while it is $280 \mathrm{~kg} / \mathrm{cm}^{2}$ in the 18 -story building. In all models, the ultimate strength of longitudinal bars is $5000 \mathrm{~kg} / \mathrm{cm} 2$. ETABS (2013) was used to design the structural models [36]. The studied buildings have a $30 \mathrm{~m} \times$ $18 \mathrm{~m}$ rectangle plan with a story height of $3.2 \mathrm{~m}$ and spans of $6 \mathrm{~m}$. In designing the building models, the story drift
TABLE 2: Gravity loads.

\begin{tabular}{lcc}
\hline Load type & Story & Roof \\
\hline Dead load $\left(\mathrm{Kg} / \mathrm{m}^{2}\right)$ & 520 & 520 \\
Live load $\left(\mathrm{Kg} / \mathrm{m}^{2}\right)$ & 250 & 150 \\
Perimeter walls $(\mathrm{Kg} / \mathrm{m})$ & 570 & 300 \\
\hline
\end{tabular}

ratios were limited to values specified by the considered code. Figure 4 shows the structural models and typical plan of buildings were considered in this study. The applied gravity loads to the structural models are presented in Table 2.

3.3. Validation of the Mathematical Model for Soil-Structure Interaction. To evaluate the validity of the employed cone model for SSI, the variation of the fundamental periods of the 12-story building model due to change in soil shear-wave velocity is presented in Table 3. As expected, an increase in soil shear-wave velocity reduces the fundamental period of the structural model. Also, one should observe that the 


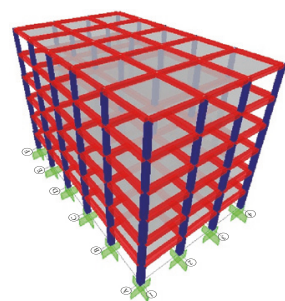

(a)

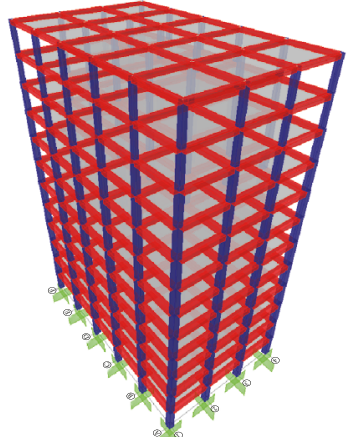

(b)

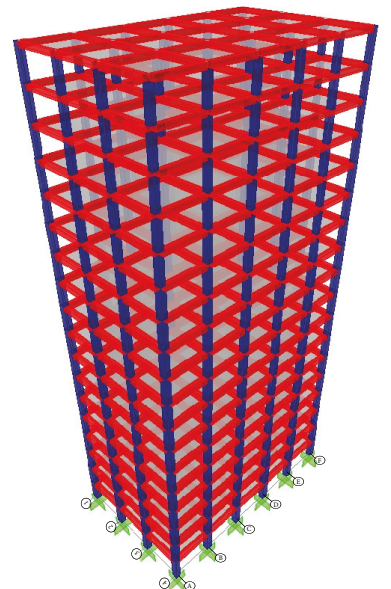

(c)

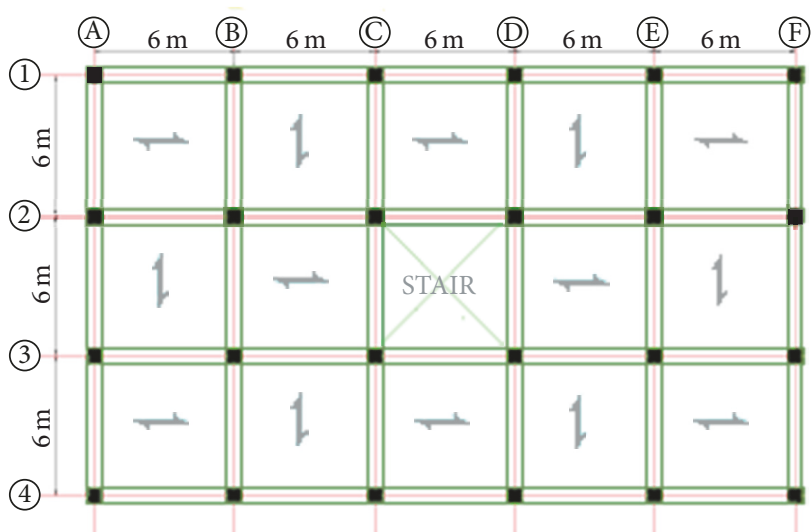

(d)

FIGURE 4: Structural elevation and plan: (a) 6-story building, (b) 12-story building, (c) 18-story building, and (d) typical plan.

fundamental period of the rigid based 12-story building becomes equal to the case with SSI for the soil shear-wave velocity of $2000 \mathrm{~m} / \mathrm{s}$ and above.

\subsection{The Earthquake Records Used for Parametric Studies. 23} pairs of far field earthquake records have been selected from PEER [37] that have mostly been used in ATC-55 (FEMA440) project [38]. Table 4 shows the characteristics of the selected earthquake records that have been registered on stiff soil (soil type D with shear-wave velocity of $180 \mathrm{~m} / \mathrm{s}$ to $360 \mathrm{~m} / \mathrm{s}$ ) resulting from events with a magnitude of 6.2 to 7.3 and fault distance of 21.2 to $50.7 \mathrm{~km}$. The selected records were normalized according to the ASCE 7-10 code [35] before being used in the extensive nonlinear dynamic time history analyses.

\section{Analysis and Results}

Following the selection and normalization of the earthquake records and preparation of the structural models, the IDA analyses were conducted using OpenSees program under the applied bidirectional seismic excitations. In the process of modeling, two-way eccentricities of $5 \%$ of the building
TABLE 3: The fundamental period of 12-story building for different soil shear wave velocities.

\begin{tabular}{lccc}
\hline$V s(\mathrm{~m} / \mathrm{sec})$ & 256 & 2000 & No SSI \\
Period $(\mathrm{sec})$ & 1.43463 & 1.3758 & 1.3753 \\
\hline
\end{tabular}

dimensions are considered by proper shifting of the mass centers of each story. In calculation of the stiffness coefficients, the correction factor for embedment was considered equal to 1 . The IDA curves were developed considering both scalar intensity measures (IMs), that is, $\operatorname{Saavg}\left(T_{1} ; \ldots ; T_{n}\right)$ and $\mathrm{Sa}\left(T_{1}, 5 \%\right)$. The spectral acceleration average (Saavg) that is described by (4) is defined as the geometric mean of the pseudospectral acceleration of an earthquake record over a certain range of periods. Figure 5 shows how to calculate Saavg for a given earthquake record response spectrum [18].

$$
\operatorname{Saavg}\left(k_{1} T_{1}, k_{2} T_{1}, \ldots, k_{n} T_{1}\right)=\left(\prod_{i=1}^{n} S_{A}\left(k_{i} T_{1}\right)\right)^{1 / n},
$$

where $T_{1}$ is the structure fundamental period and $k_{1}$ to $k_{n}$ are constants specifying lower and upper bounds used to 
TABLE 4: Characteristics of 23 pairs of far field earthquake records for the numerical analyses.

\begin{tabular}{|c|c|c|c|c|c|c|c|}
\hline Number & Date & Earthquake name & Record name & Magnitude (Ms) & Station number & PGA (g) & $V s(\mathrm{~m} / \mathrm{s})$ \\
\hline \multirow{2}{*}{1} & \multirow{2}{*}{$01 / 17 / 94$} & \multirow{2}{*}{ Northridge } & NORTHR/MUL279 & \multirow{2}{*}{6.7} & \multirow{2}{*}{90013} & 0.516 & \multirow{2}{*}{356} \\
\hline & & & NORTHR/MUL009 & & & 0.416 & \\
\hline \multirow{2}{*}{2} & \multirow{2}{*}{$01 / 17 / 94$} & \multirow{2}{*}{ Northridge } & NORTHR/LOS270 & \multirow{2}{*}{6.7} & \multirow{2}{*}{90057} & 0.482 & \multirow{2}{*}{309} \\
\hline & & & NORTHR/LOS0 & & & 0.41 & \\
\hline \multirow{2}{*}{3} & \multirow{2}{*}{$01 / 17 / 94$} & \multirow{2}{*}{ Northridge } & NORTHR/HOL90 & \multirow{2}{*}{6.7} & \multirow{2}{*}{24303} & 0.358 & \multirow{2}{*}{256} \\
\hline & & & NORTHR/HOL360 & & & 0.231 & \\
\hline \multirow{2}{*}{4} & \multirow{2}{*}{ 11/12/1999 } & \multirow{2}{*}{ Duzce, Turkey } & Duzce/BOL090 & \multirow{2}{*}{7.3} & Bolu & 0.822 & 326 \\
\hline & & & Duzce/BOL0 & & & 0.728 & \\
\hline 5 & $10 / 15 / 79$ & Imnerial Valley & IMPVALL \H-DLT352 & 69 & 6605 & 0.351 & 275 \\
\hline 3 & (10/10//9 & mperral valley & IMPVALL \H-DLT262 & 0.9 & 0000 & 0.238 & \\
\hline 6 & $10 / 15 / 79$ & Imnerial Valley & IMPVALL \H-EL1230 & 69 & 5058 & 0.38 & 196 \\
\hline & 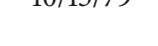 & 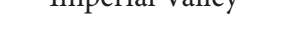 & IMPVALL \H-EL140 & 0.5 & (2000 & 0.364 & 170 \\
\hline 7 & $10 / 15 / 79$ & Imperial Valley & IMPVALL $\backslash \mathrm{H}-\mathrm{CHI} 012$ & 69 & 6621 & 0.27 & 256 \\
\hline$\gamma$ & & mimperidal valley & IMPVALL $\backslash \mathrm{H}-\mathrm{CHI} 282$ & 0.9 & 0021 & 0.254 & 250 \\
\hline 8 & $11 / 24 / 87$ & Superstition Hills(B) & SUPERST/B-CAL315 & 6.6 & 5061 & 0.247 & 208 \\
\hline 8 & $11 / 24 / 8 /$ & superstition nills(D) & SUPERST/B-CAL225 & 0.0 & 5001 & 0.18 & 208 \\
\hline 9 & $8 / 17 / 99$ & Kocaeli Turkey & KOCAELI $\backslash D Z C 270$ & 78 & Duzce & 0.358 & 276 \\
\hline 9 & $0 / 17 / 99$ & Косаеп, 1иккеу & KOCAELI \DZC180 & & Duzce & 0.312 & $2 / 0$ \\
\hline 10 & 10/01/1987 & Whittier Narrows & WHITTIER/A-BIR180 & 57 & 90079 & 0.299 & 276 \\
\hline 10 & & & WHITTIER/A-BIR090 & & & 0.243 & \\
\hline 11 & $06 / 28 / 92$ & Landers & LANDERS/YER270 & 74 & 22074 & 0.245 & 354 \\
\hline 11 & $00 / 28 / 92$ & Landers & LANDERS/YER360 & 1.4 & $2 \angle 0 / 4$ & 0.152 & 354 \\
\hline 12 & $06 / 28 / 92$ & Landers & LANDERS/CLW-TR & 74 & 23 & 0.417 & 271 \\
\hline 12 & $00 / 28 / 92$ & Landers & LANDERS/CLW-LN & 1.4 & Coolwater & 0.283 & $2 / 1$ \\
\hline 13 & $10 / 18 / 89$ & Loma Prieta & LOMAP/CAP000 & 7.1 & 47125 & 0.529 & 289 \\
\hline & & & LOMAP/CAP090 & & & 0.443 & \\
\hline 14 & $10 / 18 / 89$ & Loma Prieta & LOMAP/GO3000 & 71 & 47381 & 0.555 & 350 \\
\hline 14 & $10 / 10 / 08$ & Loma Prieta & LOMAP/GO3090 & 7.1 & $4 / 381$ & 0.367 & 500 \\
\hline 15 & $10 / 18 / 89$ & Loma Prieta & LOMAP/SLC360 & 7.1 & 1601 & 0.278 & 289 \\
\hline 10 & $10 / 10 / 09$ & Loma Preta & LOMAP/SLC270 & 7.1 & 1001 & 0.194 & 209 \\
\hline 16 & $11 / 24 / 87$ & Superstition Hills(B) & SUPERST/B-ICC000 & 6.6 & 1335 & 0.358 & 192 \\
\hline & & & SUPERST/B-BICC090 & & & 0.258 & \\
\hline 17 & $11 / 24 / 87$ & Superstition Hills(B) & SUPERST/B-POE270 & 6.6 & Poe Road & 0.446 & 208 \\
\hline 17 & & & SUPERST/B- POE360 & & & 0.3 & \\
\hline & & & CAPEMEND/RIO360 & & & 0.549 & \\
\hline 18 & $04 / 25 / 92$ & Cape Mendocino & CAPEMEND/RIO270 & 7.1 & 89324 & 0.385 & 312 \\
\hline 19 & 09/20/99 & Chi-Chi. Taiwan & CHICHI/CHY101-N & 76 & CHY101 & 0.44 & 259 \\
\hline & & & CHICHI/CHY101-W & & & 0.353 & \\
\hline 20 & $04 / 24 / 84$ & Morgan Hill & MORGAN/HD4165 & 6.1 & 1656 & 0.098 & 256 \\
\hline 20 & $04 / 24 / 84$ & Morgan пाII & MORGAN/HD4255 & 0.1 & 1030 & 0.092 & 250 \\
\hline 21 & $02 / 09 / 1971$ & San Fernando & SFERN/PEL090 & 66 & $135 \mathrm{LA}$ & 0.21 & 316 \\
\hline & & & SFERN/PEL180 & 0.6 & $135 \mathrm{LA}$ & 0.174 & \\
\hline 22 & & & COALINGA/H-C05270 & & 36227 & 0.147 & 256 \\
\hline 22 & $05 / 02 / 1983$ & Coalınga & COALINGA/H-C05360 & 6.5 & 36227 & 0.131 & 256 \\
\hline 23 & $01 / 16 / 95$ & Kobe & KOBE/SHI000 & 6.9 & Shin-Osaka & 0.243 & 256 \\
\hline $2 \mathrm{~J}$ & $01 / 10 / 95$ & Kode & KOBE/SHI090 & 0.9 & snin-usaka & 0.212 & 250 \\
\hline
\end{tabular}




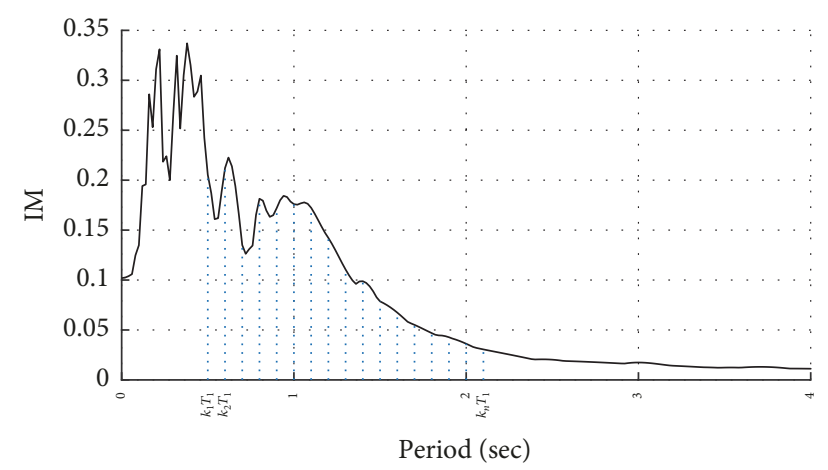

FIGURE 5: Schematic approach to calculate the average spectral acceleration from the response spectrum of a seismic record.

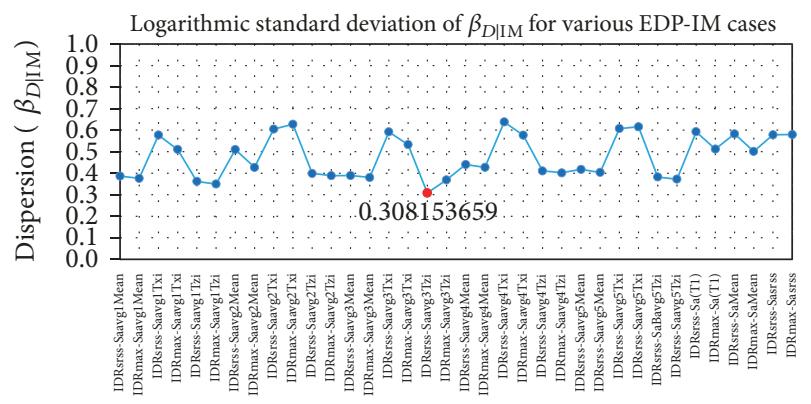

Engineering demand parameter-intensity measure, (EDP-IM)

FIgURE 6: Dispersion values for various EPD-IM scenarios in 12story building with fixed base.

determine the averaging points in the elastic acceleration spectrum of the considered record. The coefficients $k_{1}$ and $k_{n}$, respectively, introduce the effect of different modes on the dynamic behavior of structure as well as the effect of nonlinear behavior of the structural system that can be taken into account through the increased effective period of damaged system. The minimum number between the lower and upper bound for $k_{1}$ to $k_{n}$ is 10 [18]. Also, $k_{1}$ and $k_{n}$ are selected such that the response dispersion is minimized. To select the best averaging range, different values for $k_{1}$ and $k_{n}$ were evaluated based on the study conducted by Bianchini et al. [18]. It should be noted that the mentioned coefficients vary from 0.2 to 2 .

In this study, two engineering demand parameters (EDP) are considered: maximum internal drift ratio between two horizontal directions (IDRx or IDRz) and the maximum square root of the sum of the squares (SRSS) of IDRx and IDRz (IDRsrss). Also, 18 intensity measures (IMs) are chosen. According to the various engineering demand parameters and intensity measures presented in Notations, 36 EDPIM scenarios are generated to perform the incremental dynamic analysis. The dispersion of IDA curves for different mentioned EDP-IM scenarios is estimated for the selected structures. Observing dispersion is the best tool to select of EDP-IM scenario for IDA curves. A simple logarithmic linear regression model is applied to offer an efficient EDP-IM scenario using the estimation of dispersion [22]. For example, the dispersion range of $0.2-0.3$ is normally considered as an appropriate efficiency, while the range of $0.3-0.4$ is still rationally acceptable [39]. For all considered buildings, fixedbase or SSI configuration with different number of the stories, the minimum dispersion was observed for the EDP-IM scenario which corresponded to the SRSS(IDR)-Saavg and $k_{1}=0.5, k_{n}=2$. For instance, Figure 6 shows dispersion of EDP-IM scenarios (12-story structural model with a twoway eccentricity of 5\% and fixed base) which are listed in Notations.

The fragility curves of the studied building models were determined for the following two cases:

(A) $\mathrm{EDP}=\mathrm{IDR}_{\mathrm{SRSS}}$ and $\mathrm{IM}=\mathrm{Sa}\left(T_{1}, \xi=0.05\right)$.

(B) $\mathrm{EDP}=\mathrm{IDR}_{\mathrm{SRSS}}$ and $\mathrm{IM}=\operatorname{Saavg}\left(T_{z}, \xi=0.05\right)$.

4.1. Determination of Collapse Fragility Curves for the Studied Buildings. To extract the occurrence probability of collapse from IDA results, the so-called fragility curves are used. Collapse fragility curve can be considered as a cumulative distribution function (CDF) of a stochastic variable, namely, collapse capacity (Sac). Ibarra and krawinkler showed that Sac points follow a log-normal distribution; that is, $\ln \left(S_{a c}\right) \rightarrow$ $N\left(\eta_{C}, \beta_{R C}\right)$, where $\eta_{C}$ and $\beta_{R C}$ are median collapse capacity and dispersion of collapse capacity values due to different earthquake records which are numerically equal to the standard deviation of collapse capacity values [2]. For a given hazard level, like $P_{R}$, corresponding spectral acceleration can be obtained using seismic hazard curves and collapse probability can be calculated from (5), where $\eta_{C}$ and $\beta_{R C}$ are median and standard deviation of log-normal cumulative distribution function, respectively:

$$
P\left(C \mid S_{a}^{P R}\right)=\Phi\left(\frac{\ln \left(S_{a}^{P R}\right)-\ln \left(\eta_{C}\right)}{\beta_{R C}}\right) .
$$

Figures 7(a) and 7(b) present the fragility curves of the studied buildings under two-way eccentricities of the mass center corresponding to $5 \%$ of building dimensions and under the simultaneous effects of the horizontal components of the selected earthquake records with the two aforementioned IMs for the cases with fixed base and considering SSI effects.

It should be noted that the higher collapse capacity of the 6-story structure is because of its lower vulnerability to $P-\Delta$ effects in comparison with the high-rise structures. In design of this structure, an overestimation was considered to represent the design of administrative buildings. In addition, the 6- and 12-story structures are moderate moment-resisting buildings (where the 18-story structure is special momentresisting building) that increases the design base shear and leads to the higher collapse capacity values.

Since the above curves are in the form of log-normal cumulative distribution function with median $\left(\eta_{C}\right)$ and standard deviation $\left(\beta_{R C}\right)$ parameters, their values are summarized in Table 5.

It is worth mentioning that stiffness of the 6-story building is high and the structural fundamental period is low; therefore, the soil-structural interaction is not considerable. 


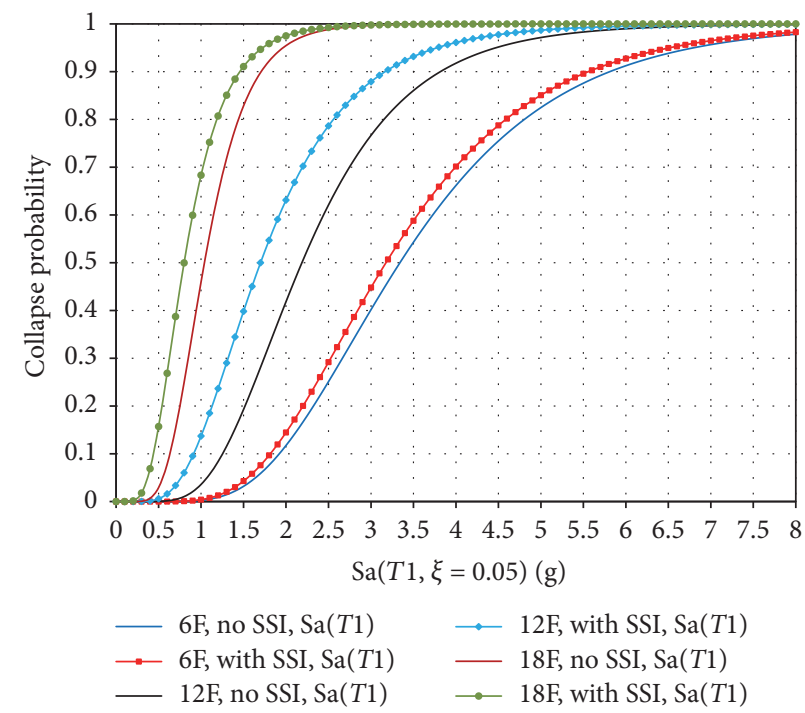

(a)

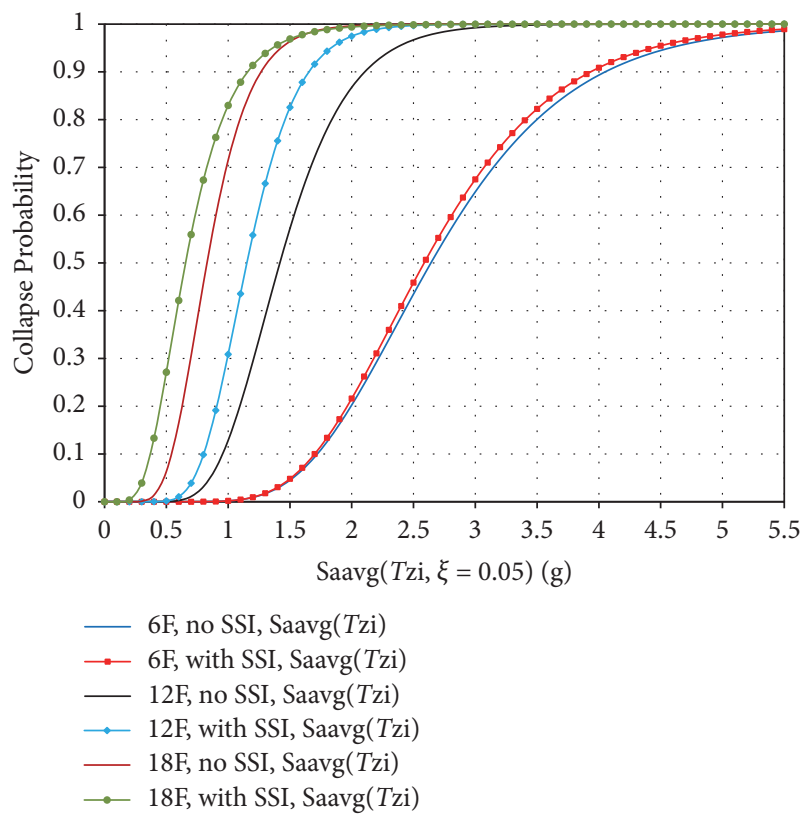

(b)

FIgURE 7: Fragility curves of the studied buildings in two states: fixed base and considering SSI. (a) $\mathrm{IM}=\mathrm{Sa}\left(T_{1}, \xi=0.05\right)$; (b) IM $=$ $\operatorname{Saavg}\left(T_{z i}, \xi=0.05\right)$.

TABLE 5: Mean and standard deviation of fragility curves of the studied buildings in different states.

\begin{tabular}{|c|c|c|c|c|c|c|c|}
\hline \multirow{2}{*}{ Type of support } & \multirow{2}{*}{ CDF parameters } & \multicolumn{3}{|c|}{$\mathrm{IM}=\mathrm{Sa}\left(T_{1}, \zeta=0.05\right)$} & \multicolumn{3}{|c|}{$\mathrm{IM}=\operatorname{Saavg}\left(T_{z i}, \zeta=0.05\right)$} \\
\hline & & 6-story & 12-story & 18-story & 6-story & 12-story & 18-story \\
\hline \multirow{2}{*}{ No SSI } & $\operatorname{Median}(\eta)$ & 3.3406 & 2.1869 & 1.0397 & 2.6408 & 1.4185 & 0.8287 \\
\hline & Standard deviation $\left(\beta_{\mathrm{RC}}\right)$ & 0.4318 & 0.4344 & 0.3867 & 0.3338 & 0.3082 & 0.3307 \\
\hline \multirow{2}{*}{ With SSI } & Median $(\eta)$ & 3.1761 & 1.7000 & 0.8003 & 2.5861 & 1.1515 & 0.6552 \\
\hline & Standard deviation $\left(\beta_{\mathrm{RC}}\right)$ & 0.4366 & 0.4852 & 0.4669 & 0.3271 & 0.2822 & 0.4439 \\
\hline \multicolumn{2}{|c|}{ Error estimation of fixed-based assumption (\%) } & $4.92 \%$ & $22.26 \%$ & $23.03 \%$ & $2.07 \%$ & $18.82 \%$ & $20.93 \%$ \\
\hline
\end{tabular}

According to Table 5, the IM values corresponding to the collapse probability of $50 \%$ (median spectral acceleration capacity) decrease, respectively, by $4.92 \%, 22.26 \%$, and $23.03 \%$ for 6-, 12-, and 18-story buildings for $\mathrm{IM}=\mathrm{Sa}\left(T_{1}, \zeta=0.05\right)$ and by $2.07 \%, 18.82$, and $20.93 \%$ for IM = Saavg. Therefore, based on the observed reduction percentage in this study, the effect of SSI on the median amount of the fragility curve for 18-story building is higher than the 12-story building. In addition, selecting Saavg instead of $\mathrm{Sa}\left(T_{1}, \zeta=0.05\right)$ can decrease the standard deviation of the fragility curves. In other words, Saavg is more efficient than $\mathrm{Sa}\left(T_{1}, \zeta=0.05\right)$ to be used as an IM.

4.2. Mean Annual Frequency (MAF) of Collapse Based on $S a\left(T_{1}, \zeta=0.05\right)$. The mean annual frequency (MAF) of collapse is derived by integration of the building collapse fragility curve relative to the seismic hazard curve defined as

$$
\lambda_{C}=\int P_{C \mid x}\left|d \lambda_{I M}(x)\right| .
$$

Closed-form solution introduced by Jalayer was used to estimate the MAF of collapse [40]. The closed-form solution is shown in (7), where $k$ is seismic hazard curve slope in the $\log$ - $\log$ domain, and $\eta_{C}$ and $\beta_{R C}$ are median and standard deviation of collapse fragility curve, respectively:

$$
\lambda_{C}=\left[\lambda_{\mathrm{Sa}}\left(\eta_{\mathrm{C}}\right)\right]\left[\exp \left(\frac{1}{2} k^{2} \beta_{R C}^{2}\right)\right] .
$$

To determine the MAF of collapse for buildings, seismic hazard curve is required. To this end, the seismic hazard curve was derived from Probabilistic Seismic Hazard Analysis (PSHA) corresponding to fundamental period of studied buildings. In addition, seismic hazard curve can be estimated using a linear relation in log-log domain shown as follows:

$$
\lambda_{S_{a}}=k_{0} S_{a}^{-k}
$$

The collapse probability of the building due to seismic action has been recommended to be less than $2 \%$ in a 50 -year 


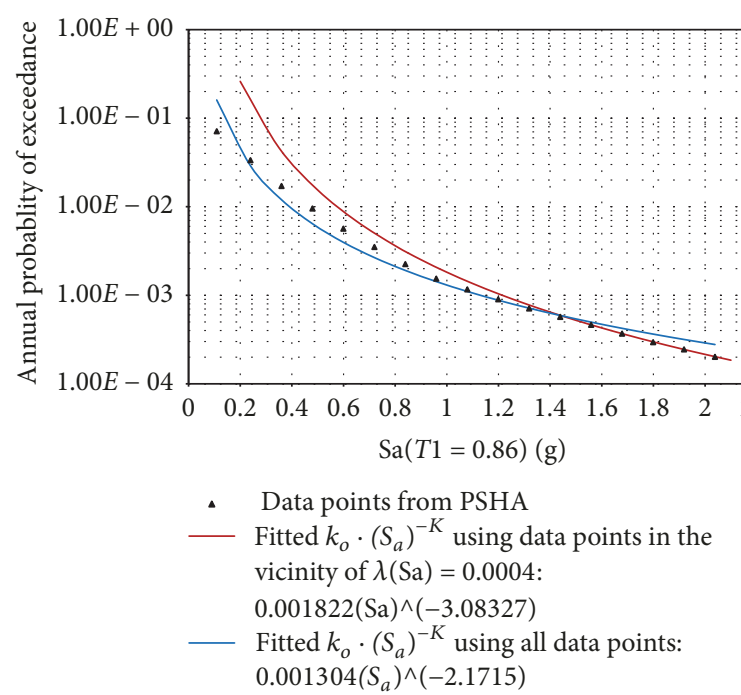

(a)

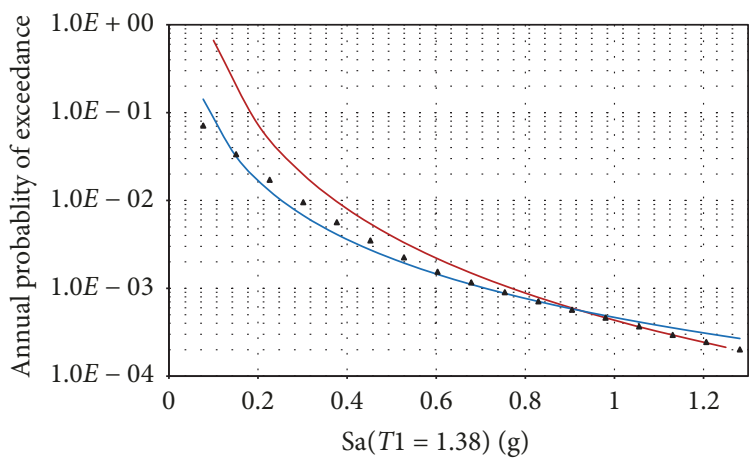

- Data points from PSHA

- Fitted $k_{o} \cdot\left(S_{a}\right)^{-K}$ using data points in the vicinity of $\lambda(\mathrm{Sa})=0.0004$ : $0.0004335(\mathrm{Sa})^{\wedge}(-3.1846)$

_- Fitted $k_{o} \cdot\left(S_{a}\right)^{-K}$ using all data points: $0.0004664\left(S_{a}\right)^{\wedge}(-2.2293)$

(b)

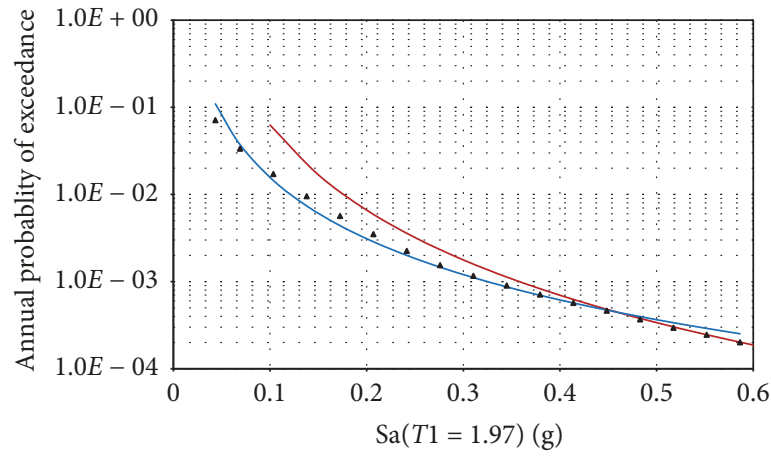

- Data points from PSHA

- Fitted $k_{o} \cdot\left(S_{a}\right)^{-K}$ using data points in the vicinity of $\lambda(\mathrm{Sa})=0.0004$ : $0.0000357(\mathrm{Sa}) \wedge(-3.244)$

- Fitted $k_{o} \cdot\left(S_{a}\right)^{-K}$ using all data points: $0.00007252\left(S_{a}\right) \wedge(-2.3342)$

(c)

FIGURE 8: Seismic hazard curve for the location: (a) period $(T 1=0.86 \mathrm{sec})$ of the 6 -story building, (b) period $(T 1=1.38 \mathrm{sec})$ of the 12 -story building, and (c) period $\left(T_{1}=1.97 \mathrm{sec}\right)$ of the 18-story building.

period with $95 \%$ confidence for this purpose by SAC/FEMA guidelines [41]. This objective translates into limiting the MAF of collapse to 0.0004 (with $95 \%$ confidence) assuming a Poisson process for collapse occurrence. The SAC/FEMA guidelines do not include a target that addresses collapse at a specific hazard level. In this section, the $k_{0}$ and $k$ parameters were obtained by fitting a linear regression model in log-log domain for whole hazard curve and a local zone in the vicinity of $\lambda\left(S_{a}\right)=0.0004$ (Figure 8). These estimated values for $k$ and $k_{0}$ parameters were used to estimate the MAF of collapse using the closed-form solution of (7). Figures 8(a)-8(c) show the data points representing the seismic hazard curve for the location of the studied buildings in the high-hazard level region of Tehran. The blue colored curves show linear regression models using all data points and the red colored curves show linear regression models using a local zone in the vicinity of 0.0004 hazard level.

Table 6 shows the values of mean annual frequency (MAF) of collapse estimated using directly applying the numerical integration to (6) and using the closed-form solution of (7) for the three studied structural models. Additionally, for spotting the most important zone of the integrand in (7), the calculation of the MAF of collapse using the closed-form solution has been obtained by fitting the linear regression model to both whole hazard curve and a local zone in the vicinity of 0.0004 hazard level and the results are shown in Table 6.

As seen in Table 6, solving the closed-form solution of (7) using the linear regression model to whole hazard curve overestimates the MAF of collapse in comparison with numerical 
TABLE 6: Comparison between MAF of collapse obtained from (6) and (7) in studied building with fixed base.

\begin{tabular}{lccc}
\hline $\begin{array}{l}\text { Number of } \\
\text { stories }\end{array}$ & $\begin{array}{c}\text { Numerical } \\
\text { integration } \\
\text { equation }(6)\end{array}$ & $\begin{array}{c}\text { Closed-form solution equation }(7) \\
\text { Fitted } k_{0}(\mathrm{Sa})^{-k} \text { using data } \\
\text { points in the vicinity of } \\
\lambda(\mathrm{Sa})=0.0004\end{array}$ & $\begin{array}{c}\text { Fitted } k_{0}(\mathrm{Sa})^{-k} \text { using all } \\
\text { data points of hazard } \\
\text { curve }\end{array}$ \\
\hline 6-story & $1.2882 \times 10^{-4}$ & $1.0724 \times 10^{-4}$ & $1.4751 \times 10^{-4}$ \\
12 -story & $1.1436 \times 10^{-4}$ & $9.3398 \times 10^{-5}$ & $1.3024 \times 10^{-4}$ \\
18 -story & $8.785 \times 10^{-5}$ & $6.911 \times 10^{-5}$ & $9.9589 \times 10^{-5}$ \\
\hline
\end{tabular}

integration equation (6). However, solving the closed-form solution of (7) using the linear regression model to local zone of vicinity of $\lambda(\mathrm{Sa})=0.0004$ underestimates the MAF of collapse compared to using numerical integration equation (6). The difference between the results obtained from (6) or (7) is construed as the relative accuracy of the closed-form solution which is developed for solution of (6) by (7).

In Table 6, it is surprising that, unlike values derived from fragility curves, the collapse probability of the highstory buildings decreases by taking seismic hazard values into account in MAF of collapse calculations whereas this collapse probability will be high if such seismic hazard values are ignored. Therefore, high-rise structures have less collapse probability. The reduction of structure's fundamental period increases the seismic hazard and on the other hand decreases the likelihood of exceeding the collapse performance level caused. This is the reason behind the increase of MAF of collapse in short-story buildings.

\section{Conclusions}

Assuming nonlinear behavior for steel and concrete materials and a two-way eccentricity of mass center, corresponding to $5 \%$ of the building dimension at every side, this study modeled three 6-, 12-, and 18-story RC moment-resisting buildings. Incremental dynamic analysis (IDA) was conducted to take the uncertainties of earthquake records into account. The buildings performance was studied for fixedbase and SSI consideration using seismic demand probabilistic analysis. In addition, the efficiency of two scalar IMs was evaluated. It could be concluded that selecting Saavg reduces the uncertainty due to record-to-record variability in seismic behavior study and increases the results reliability. This is because it considers the effects of high modes on dynamic behavior of inelastic structural system as well as the effect of system response on nonlinear region, which is accompanied with increased effective period of the damaged system. It should be noted that no fixed period range is selected and it can be different from structure to structure. Additionally, in 6-story building (short structure), fixedbase assumption leads to an error range by $2.07 \%-4.92 \%$ in the IM value corresponding to the collapse probability of $50 \%$ which is negligible compared to SSI effects. Moreover, in 12- and 18-story buildings (high-rise buildings), fixedbase assumption leads to the overestimation range of IM value by $18.82 \%-22.26 \%$ and $20.93 \%-23.09 \%$ in the $\log$ normal cumulative distribution function of fragility curves compared to SSI effects. This difference cannot be neglected. The MAF of collapse for the studied buildings were obtained (numerical integration and solving the closed-form solution) by integrating the structures' collapse fragility curve over the seismic hazard curve for the location of the structures. Accordingly, it is observed that, unlike fragility curve values, considering seismic hazard for calculation of mean annual frequency of collapse decreases the collapse probability of the high-story buildings whereas this probability is higher when no seismic hazard is considered in fragility curves.

The level of the accuracy of the estimated MAF of collapse using closed-form solution depends on the linear regression model whereas it was obtained over the whole hazard curve or a vicinity of $\lambda(\mathrm{Sa})=0.0004$. Therefore, using all data points of hazard curve in linear regression model leads to the overestimation of the MAF of collapse. In other words, the MAF of collapse by solving the closed-form solution using all the data points of hazard curve was overestimated in comparison with numerical integration.

\section{Notations}

Engineering Demand Parameters (EDP) and Intensity Measures (IMs) Considered Used in This Study

IDRmax: Maximum internal drift ratio between two horizontal directions (IDRx or IDRz)

IDRsrss: Maximum square root of the sum of the squares of internal drift ratio in $x$ and $y$ axes direction

$\mathrm{Sa}\left(T_{1}\right): \quad$ Elastic spectral acceleration in fundamental period of a structure for $5 \%$ of critical damping

Sasrss: $\quad$ Square root of the sum of the squares of the pseudospectral acceleration over fundamental and second periods of a structure for $5 \%$ of critical damping: $\sqrt{\mathrm{Sa}(T 1)^{2}+\mathrm{Sa}(T 2)^{2}}$

SaMean: Geometric mean of the pseudospectral acceleration over fundamental and second periods a structure for $5 \%$ of critical damping: $\sqrt{\mathrm{Sa}(T 1) \cdot \mathrm{Sa}(T 2)}$

Saavg1Tzi: Spectral acceleration average of an earthquake recorded over a certain range of fundamental period corresponding to $k_{1}=0.2$ and $k_{n}=2$ 
Saavg1Txi: Spectral acceleration average of an earthquake recorded over a certain range of second mode period corresponding to $k_{1}=0.2$ and $k_{n}=2$

Saavg1Mean: Geometric mean of Saavg1Txi and Saavg1Tzi: $\sqrt{\text { Saavg1Txi } \times \text { Saavg1Txi }}$

Saavg2Tzi: Spectral acceleration average of an earthquake recorded over a certain range of fundamental period corresponding to $k_{1}=0.2$ and $k_{n}=1.5$

Saavg2Txi: Spectral acceleration average of an earthquake recorded over a certain range of second mode period corresponding to $k_{1}=0.2$ and $k_{n}=1.5$

Saavg2Mean: Geometric mean of Saavg2Txi and Saavg2Tzi: $\sqrt{\text { Saavg2Txi } \times \text { Saavg2Txi }}$

Saavg3Tzi: Spectral acceleration average of an earthquake recorded over a certain range of fundamental period corresponding to $k_{1}=0.5$ and $k_{n}=2$

Saavg3Txi: Spectral acceleration average of an earthquake recorded over a certain range of second mode period corresponding to $k_{1}=0.5$ and $k_{n}=2$

Saavg3Mean: Geometric mean of Saavg3Txi and Saavg3Tzi: $\sqrt{\text { Saavg3Txi } \times \text { Saavg3Txi }}$

Saavg4Tzi: Spectral acceleration average of an earthquake recorded over a certain range of fundamental period corresponding to $k_{1}=0.5$ and $k_{n}=1.5$

Saavg4Txi: Spectral acceleration average of an earthquake recorded over a certain range of second mode period corresponding to $k_{1}=0.5$ and $k_{n}=1.5$

Saavg4Mean: Geometric mean of Saavg4Txi and Saavg4Tzi: $\sqrt{\text { Saavg4Txi } \times \text { Saavg4Txi }}$

Saavg5Tzi: Spectral acceleration average of an earthquake recorded over a certain range of fundamental period corresponding to $k_{1}=0.3$ and $k_{n}=1.7$

Saavg5Txi: Spectral acceleration average of an earthquake recorded over a certain range of second mode period corresponding to $k_{1}=0.3$ and $k_{n}=1.7$

Saavg5Mean: Geometric mean of Saavg5Txi and Saavg5Tzi: $\sqrt{\text { Saavg5Txi } \times \text { Saavg5Txi. }}$

\section{Conflicts of Interest}

The authors declare that they have no conflicts of interest.

\section{References}

[1] C. A. Cornell, F. Jalayer, R. O. Hamburger, and D. A. Foutch, "Probabilistic basis for 2000 SAC federal emergency management agency steel moment frame guidelines," Journal of Structural Engineering, vol. 128, no. 4, pp. 526-533, 2002.

[2] L. F. Ibarra and H. Krawinkler, Global Collapse of Frame Structures under Seismic Excitations, Pacific Earthquake Engineering Research Center, Berkeley, CA, USA, 2005.
[3] C. B. Haselton, A. B. Liel, B. S. Dean, J. H. Chou, and G. G. Deierlein, "Seismic collapse safety and behavior of modern reinforced concrete moment frame buildings," in Structural Engineering Research Frontiers, pp. 1-14, 2007.

[4] F. Zareian and H. Krawinkler, "Assessment of probability of collapse and design for collapse safety," Earthquake Engineering \& Structural Dynamics, vol. 36, no. 13, pp. 1901-1914, 2007.

[5] M. Stoica, R. A. Medina, and R. H. McCuen, "Improved probabilistic quantification of drift demands for seismic evaluation," Structural Safety, vol. 29, no. 2, pp. 132-145, 2007.

[6] R. Chandramohan, J. W. Baker, and G. G. Deierlein, "Impact of hazard-consistent ground motion duration in structural collapse risk assessment," Earthquake Engineering \& Structural Dynamics, vol. 45, no. 8, pp. 1357-1379, 2016.

[7] P. H. Galanis and J. P. Moehle, "Development of collapse indicators for risk assessment of older-type reinforced concrete buildings," Earthquake Spectra, vol. 31, no. 4, pp. 1991-2006, 2015.

[8] F. Jalayer and C. A. Cornell, "A technical framework for probability-based demand and capacity factor (DCFD) seismic formats," RMS, 2003.

[9] F. Jalayer, H. Ebrahimian, A. Miano, G. Manfredi, and H. Sezen, "Analytical fragility assessment using unscaled ground motion records," Earthquake Engineering \& Structural Dynamics, vol. 46, no. 15, pp. 2639-2663, 2017.

[10] C. B. Haselton and G. G. Deierlein, "Assessing seismic collapse safety o f modern reinforced concrete moment-frame buildings," PEER Report, Pacific Earthquake Engineering Research Center College of Engineering University of California, Berkeley, CA, USA, 2007.

[11] C. B. Haselton, A. B. Liel, G. G. Deierlein, B. S. Dean, and J. H. Chou, "Seismic collapse safety of reinforced concrete buildings. I: Assessment of ductile moment frames," Journal of Structural Engineering, vol. 137, no. 4, pp. 481-491, 2011.

[12] D. G. Lignos, T. Hikino, Y. Matsuoka, and M. Nakashima, "Collapse assessment of steel moment frames based on E-defense full-scale shake table collapse tests," Journal of Structural Engineering (United States), vol. 139, no. 1, pp. 120-132, 2013.

[13] P. Rajeev and S. Tesfamariam, "Seismic fragilities for reinforced concrete buildings with consideration of irregularities," Structural Safety, vol. 39, pp. 1-13, 2012.

[14] M. Palermo, R. R. Hernandez, S. Mazzoni, and T. Trombetti, "On the seismic behavior of a reinforced concrete building with masonry infills collapsed during the 2009 Laquila earthquake," Earthquake and Structures, vol. 6, no. 1, pp. 45-69, 2014.

[15] D. Vamvatsikos and C. Allin Cornell, "Incremental dynamic analysis," Earthquake Engineering \& Structural Dynamics, vol. 31, no. 3, pp. 491-514, 2002.

[16] R. Villaverde, "Methods to assess the seismic collapse capacity of building structures: State of the art," Journal of Structural Engineering, vol. 133, no. 1, pp. 57-66, 2007.

[17] N. Shome and C. A. Cornell, "Probabilistic seismic demand analysis of non-linear structures," Report No. RMS-35, Stanford University, Stanford, CA, USA, 1999.

[18] M. Bianchini, P. P. Diotallevi, and J. W. Baker, "Prediction of inelastic structural response using an average of spectral accelerations," in Proceedings of the 10th International Conference on Structural Safety and Reliability (ICOSSAR09), pp. 13-17, Osaka, Japan, 2009.

[19] M. Kohrangi, P. Bazzurro, and D. Vamvatsikos, "Vector and scalar IMs in structural response estimation, Part I: Hazard analysis," Earthquake Spectra, vol. 32, no. 3, pp. 1507-1524, 2016. 
[20] L. Eads, E. Miranda, and D. G. Lignos, "Average spectral acceleration as an intensity measure for collapse risk assessment," Earthquake Engineering \& Structural Dynamics, vol. 44, no. 12, pp. 2057-2073, 2015.

[21] M. Kohrangi, P. Bazzurro, D. Vamvatsikos, and A. Spillatura, "Conditional spectrum-based ground motion record selection using average spectral acceleration," Earthquake Engineering \& Structural Dynamics, vol. 46, no. 10, pp. 1667-1685, 2017.

[22] H. Ebrahimian, F. Jalayer, A. Lucchini, F. Mollaioli, and G. Manfredi, "Preliminary ranking of alternative scalar and vector intensity measures of ground shaking," Bulletin of Earthquake Engineering, vol. 13, no. 10, pp. 2805-2840, 2015.

[23] N. Luco and C. A. Cornell, "Structure-specific scalar intensity measures for near-source and ordinary earthquake ground motions," Earthquake Spectra, vol. 23, no. 2, pp. 357-392, 2007.

[24] OpenSees, Open System for Earthquake Engineering Simulation: OpenSees, University of Berkeley, Berkeley, CA, USA, 2011.

[25] V. Terezic, Force-based element vs. Displacement-based element, Pacific Earthquake Engineering Research Center (PEER), University of California, Berkeley, CA, USA, 2011.

[26] E. Spacone, F. C. Filippou, and F. F. Taucer, "Fibre beam-column model for non-linear analysis of R/C frames: part I. Formulation," Earthquake Engineering \& Structural Dynamics, vol. 25, no. 7, pp. 711-725, 1996.

[27] E. Spacone, F. C. Filippou, and F. F. Taucer, "Fibre beam-column model for non-linear analysis of $\mathrm{r} / \mathrm{c}$ frames: part ii. applications," Earthquake Engineering \& Structural Dynamics, vol. 25, no. 7, pp. 727-742, 1996.

[28] J. B. Mander, M. J. N. Priestley, and R. Park, "Observed stressstrain behavior of confined concrete," Journal of Structural Engineering, vol. 114, no. 8, pp. 1827-1849, 1988.

[29] KSU-RC, KSU-RC: Moment-Curvature, Force and Interaction Analysis of Reinforced Concrete Member, V 1.0.11, Inc, Kansas State University, Kansas, USA.

[30] F. Khoshnoudian, E. Ahmadi, M. Kiani, and M. H. Tehrani, "Dynamic instability of Soil-SDOF structure systems under farfault earthquakes," Earthquake Spectra, vol. 31, no. 4, pp. 24192441, 2015.

[31] F. Behnamfar and M. Banizadeh, "Effects of soil-structure interaction on distribution of seismic vulnerability in RC structures," Soil Dynamics and Earthquake Engineering, vol. 80, pp. 73-86, 2016.

[32] H. Shakib and F. Homaei, "Probabilistic seismic performance assessment of the soil-structure interaction effect on seismic response of mid-rise setback steel buildings," Bulletin of Earthquake Engineering, vol. 15, no. 7, pp. 2827-2851, 2017.

[33] J. P. Wolf, "Cone models as a strength of materials approach to foundation vibration," in Proceedings of the 10th European Conference on Earthq. Eng., A. A. Balkea, Ed., pp. 1-10, Vienna, Austria, 1994.

[34] ACI Committee, American Concrete Institute, and International Organization for Standardization, Building code requirements for structural concrete (ACI 318-08) and commentary, American Concrete Institute, 2008.

[35] ASCE 7-10, Minimum Design Loads for Buildings and Other Structures, American Society of Civil Engineers, Reston, VA, USA, 2010.

[36] ETABS, Structural Analysis Program, Computers and Structures Inc., Berkeley, CA, USA, 2013.

[37] Pacific Earthquake Engineering Research Center (PEER), PEER Next Generation Attenuation (NGA) Database, 2013, https:// ngawest2.berkeley.edu.
[38] Federal Emergency Management Agency (FEMA), "Improvement of nonlinear static seismic procedures," Report No. FEMA-440, Federal Emergency Management Agency, Washington, DC, USA.

[39] F. Mollaioli, A. Lucchini, Y. Cheng, and G. Monti, "Intensity measures for the seismic response prediction of base-isolated buildings," Bulletin of Earthquake Engineering, vol. 11, no. 5, pp. 1841-1866, 2013.

[40] F. Jalayer, Direct probabilistic seismic analysis: implementing non-linear dynamic assessments [Ph.D. dissertation], Stanford University, 2003.

[41] Federal Emergency Management Agency (FEMA), "State of the art report on performance prediction and evaluation of steel moment-frame buildings," Report No. FEMA-355F, Federal Emergency Management Agency, Washington, DC, USA, 2000. 


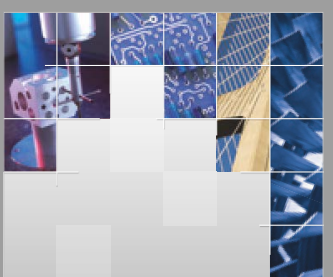

\section{Enfincering}
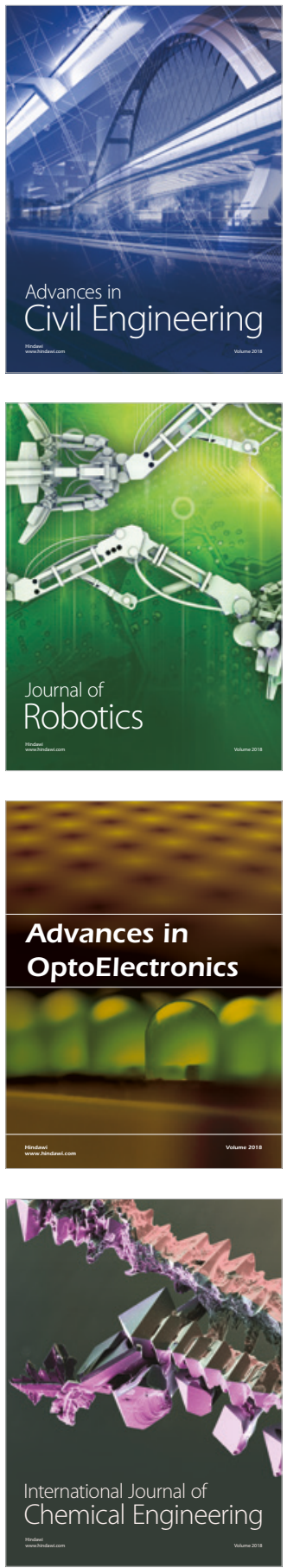

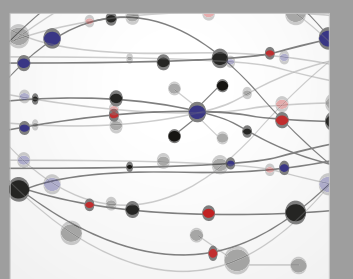

\section{Rotating \\ Machinery}

The Scientific World Journal

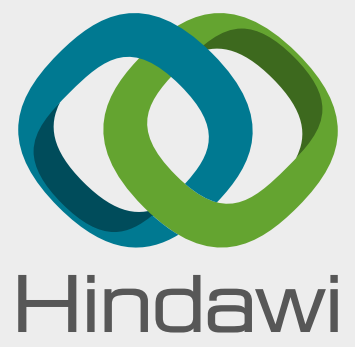

Submit your manuscripts at

www.hindawi.com
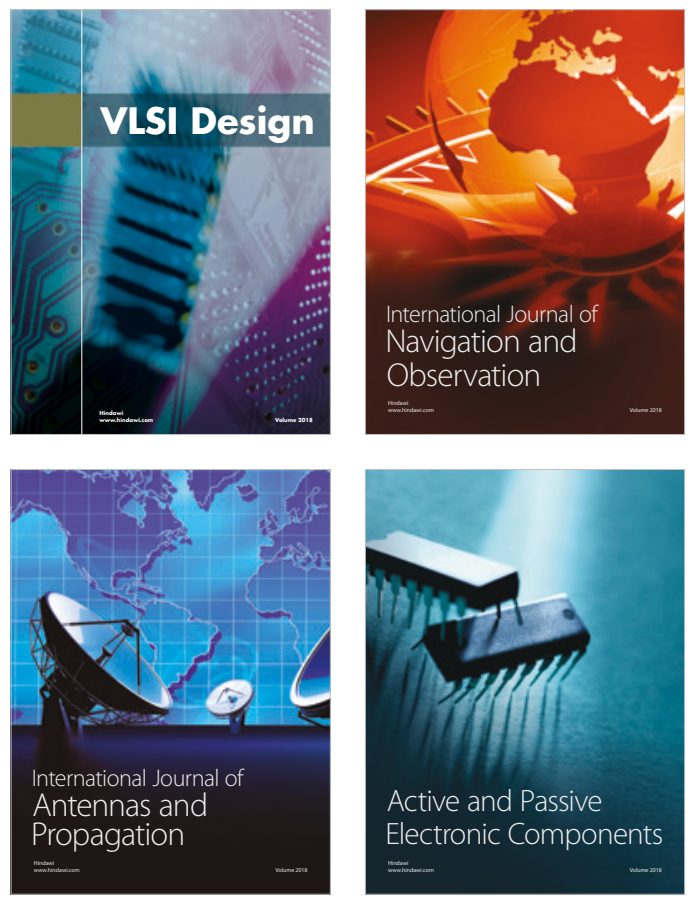
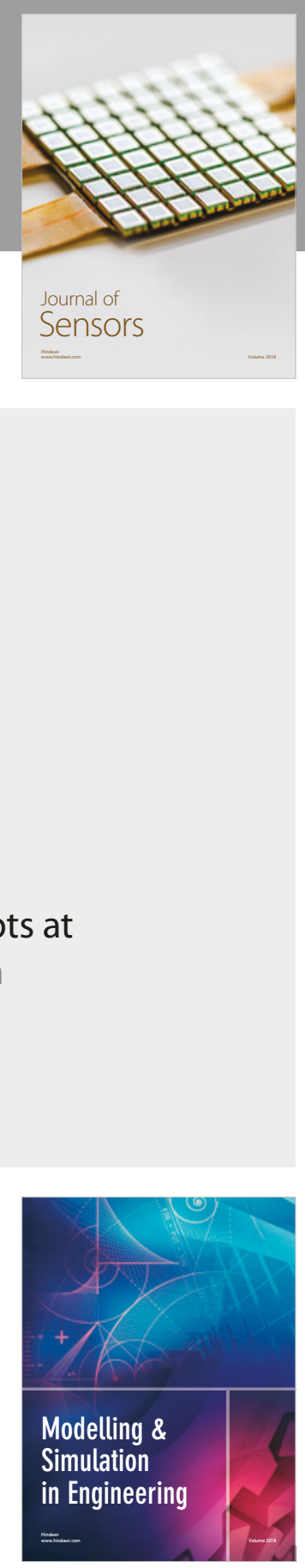

\section{Advances \\ Multimedia}
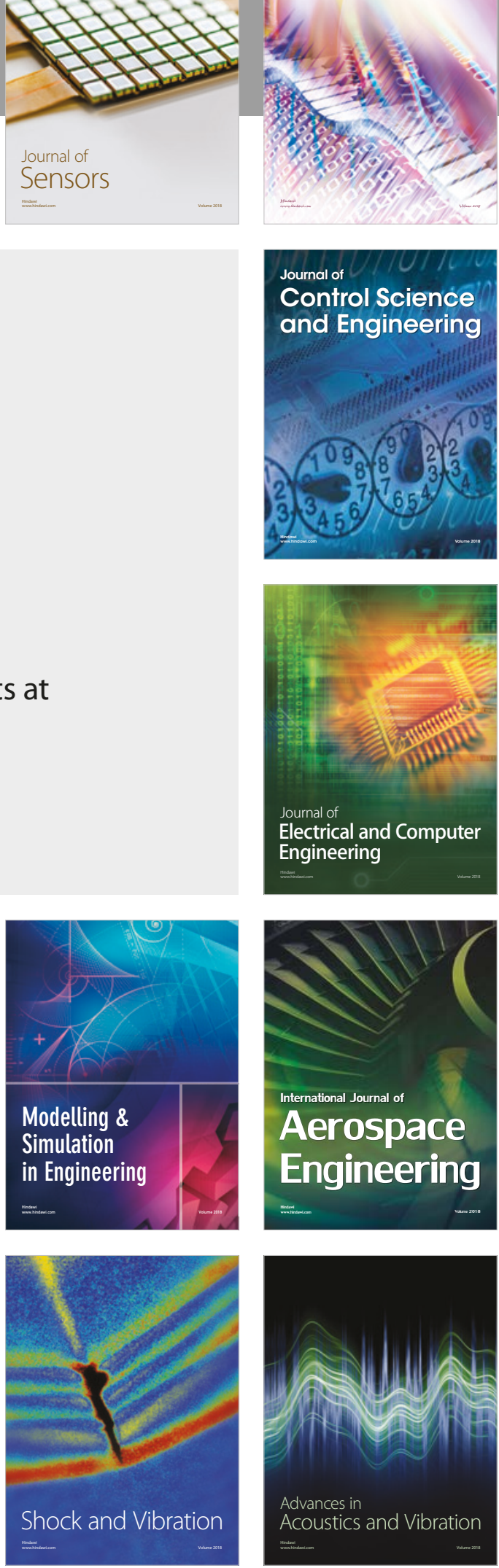